\title{
Terminally-Crosslinked Sulfonated Poly(fluorenyl ether sulfone) as a Polymer Electrolyte Membrane for both PEMFC and DMFC Application
}

\author{
Roshni Lilly Thankamony, Green Baek, Hyoung-Juhn Kim, ${ }^{\dagger}$ Sukwoo Nam, ${ }^{\dagger}$ and Tae-Hyun Kim* \\ Department of Chemistry, University of Incheon, Incheon 406-840, Korea. *E-mail: tkim@incheon.ac.kr \\ ${ }^{\dagger}$ Fuel Cell Research Center, Korea Institute of Science and Technology, Seoul 136-791, Korea \\ Received May 25, 2010, Accepted June 23, 2010
}

Key Words: Polymer electrolyte membrane, Sulfonated poly(fluorenyl ether sulfone), Terminal crosslinking, Proton conductivity, Methanol crossover

Proton exchange membrane (PEM) is a main component of the proton exchange membrane fuel cells (PEMFCs) and direct methanol fuel cells (DMFCs) for transferring protons from anode to cathode as well as providing a barrier to the fuel gas between two electrodes. Some specific limitations for the wellknown perfluorinated membranes including high cost, high methanol permeability, and loss of the preferable properties at high temperature $\left(80^{\circ} \mathrm{C}\right)$ demand a search for alternative PEMs. ${ }^{1-3}$

Sulfonated aromatic polymers have been widely studied as one of the alternatives to Nafion ${ }^{\circledR}$ due to their good physical properties and moderate proton conductivity. ${ }^{4-6}$ These properties have been shown to depend on the degree of sulfonation of the aromatic polymer: a high degree of sulfonation improves the proton conductivity, whereas degraded physical properties and increased methanol crossover are inevitably obtained for the highly sulfonated polymers.

Crosslinking has often been used as an efficient means to lower methanol crossover and to enhance properties of the polymers. ${ }^{7-9}$ However, reduced proton conductivity is accompanied for most cases mainly due to the loss of sulfonic acid groups during thermal curing for the covalently crosslinked polymers and low water absorption for the acid-base type crosslinked polymers. Only a few reports have, indeed, presented membranes with high proton conductivity and low methanol permeability, especially at enhanced temperature..$^{10,11}$

In a fusion of the benefits of both sulfonated poly(ether sulfone)s and crosslinking, we have recently introduced a novel terminally-crosslinked polymer system. ${ }^{12,13}$ Unlike a majority of the crosslinked membranes, our sulfonated polyarylenes were crosslinked only at the terminus of the polymer main chain by an azide-assisted thermal curing. The resultant terminally-crosslinked sulfonated poly(ether sulfone)s (PESs) displayed an exceptionally high proton conductivity especially at elevated temperatures, and yet maintained most of their structural integrity. Nevertheless, the rather high methanol permeability at increased temperature and low dimensional stability limit the use of our terminally-crosslinked membranes for DMFC application.

We report herein a new terminally-crosslinked polymer having a fluorenyl moiety as a dimensionally stable and highly selective polymer electrolyte membrane for proton over methanol transport even at increased temperature.

The hydroxy-terminated poly(fluorenyl ether sulfone) having fluorenylbiphenyl unit 1 was first synthesized by polycondensation of fluorenylbiphenol (FBP) and hydroquinone sulfonic acid (HQS) with fluorophenyl sulfone (FPS) with a slight excess of a dihydroxy monomer (Scheme 1). Following allylation of

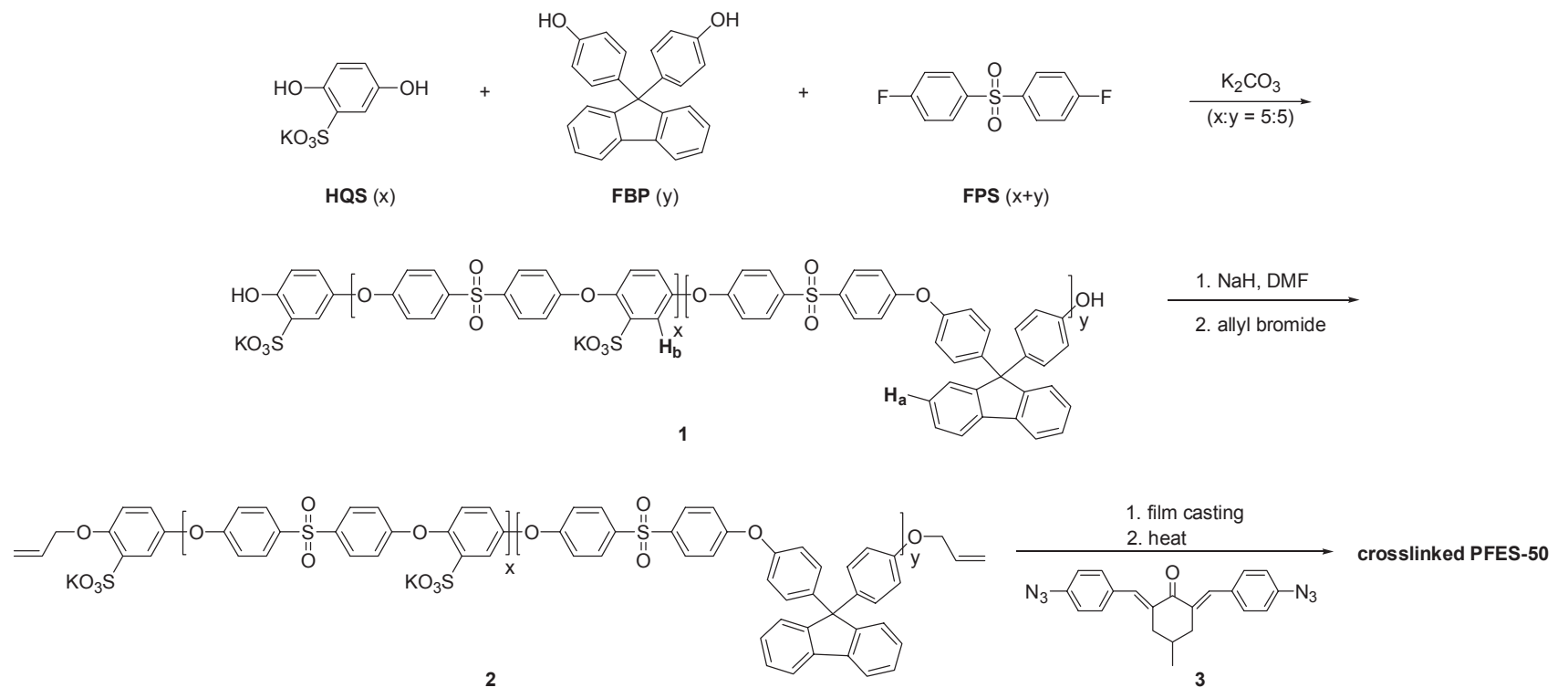

Scheme 1. Schematic representation for the preparation of the crosslinked poly(fluorenyl ether sulfone) (PFES-50). 


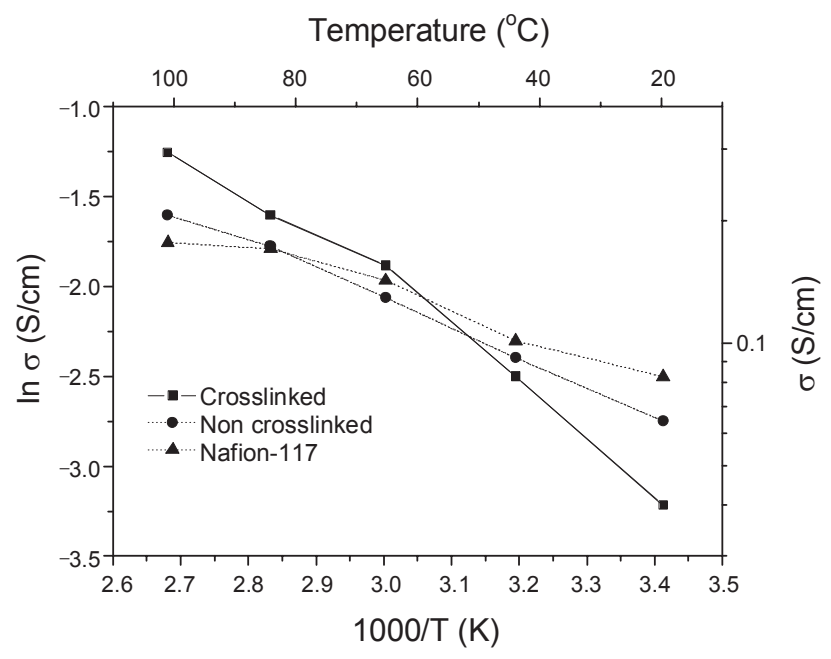

Figure 1. Arrhenius plots of conductivity versus temperature.

the terminal hydroxyls afforded the reactive allyl-terminated sulfonated poly(fluorenyl ether sulfone) (PFES) 2.

Composition (x:y) of the random copolymer 1 was confirmed by the relative ${ }^{1} \mathrm{H}-\mathrm{NMR}$ absorption peak areas between $\mathrm{H}_{\mathrm{a}}$ (7.16 ppm) and $\mathrm{H}_{\mathrm{b}}$ (7.46 ppm) illustrated in Scheme 1, and was found to be $5: 5$ ( $\mathrm{x}: \mathrm{y}=5: 5$; PFES-50).

The network structure was achieved in the same manner as previously reported using the allyl-terminated sulfonated poly (fluorenyl ether sulfone) (PFES-50) 2 and bis(aryl azide) 3. ${ }^{12,13}$ For comparison, sulfonated poly(fluorenyl ether sulfone) (PFES$50 \mathrm{n})$ with terminal allyl group was also prepared in the same method except the addition of the crosslinker 3 during the film casting. The transparent and flexible membrane prepared from sulfonated PFES-50 was not soluble in most organic solvents including DMF and DMSO, whereas its non-crosslinked counterpart PFES-50n was slowly dissolved.

Proton conductivity of the crosslinked membrane (PFES-50) and its azide-free film (PFES-50n) was measured at temperature ranges from 20 to $100{ }^{\circ} \mathrm{C}$ at $100 \% \mathrm{RH}$, and compared with Nafion ${ }^{\circledR}-117$ (Figure 1). The crosslinked film, having the originally lowest value due to the hydrophobic network, displayed much greater conductivity increase at elevated temperatures. The conductivity of $0.28 \mathrm{~S} / \mathrm{cm}$ at $100{ }^{\circ} \mathrm{C}$ for PFES-50 was higher than both non-crosslinked film $(0.20 \mathrm{~S} / \mathrm{cm})$ and Nafion ${ }^{\circledR}(0.17$ $\mathrm{S} / \mathrm{cm})$. This indicates that the influence of temperature on the proton conductivity is much higher than that of its non-crosslinked counterpart and Nafion ${ }^{\circledR}$. This very unusual phenomenon has not been reported for other crosslinked polymers, and is ascribed to its structural reorganization, occurred at hydrated and heated conditions. ${ }^{14}$

In addition, very low methanol diffusion coefficients were obtained for the crosslinked PFES-50 both at 20 and $60{ }^{\circ} \mathrm{C}(1 \times$ $10^{-8} \mathrm{~cm}^{2} / \mathrm{s}$ at $20{ }^{\circ} \mathrm{C}$ and $8.8 \times 10^{-8} \mathrm{~cm}^{2} / \mathrm{s}$ at $60{ }^{\circ} \mathrm{C}$ ).

The high proton conductivity and low methanol permeability of PFES-50 resulted in good selectivity as a polymer electrolyte membrane for direct methanol fuel cell as well. Indeed, selectivity for the crosslinked membrane (PFES-50) was more than 136 times than that of Nafion ${ }^{\circledR}$ at rt. and 81 times at $60{ }^{\circ} \mathrm{C}$. To the best of our knowledge, this is the highest selectivity for the crosslinked membranes.

Another significant feature of the crosslinked membrane is its high dimensional stability, which was investigated by comparing a swelling ratio of the membrane after treating in heated $\left(80{ }^{\circ} \mathrm{C}\right)$ water for $24 \mathrm{~h}$. The crosslinked membrane displayed smaller changes than its azide-free counterpart and Nafion ${ }^{\circledR} .15$ This is, indeed, a significant improvement as most crosslinked membranes suffer from deteriorating dimensional properties at heated and hydrated conditions. The bulky fluorenyl unit, combined with the minimized crosslinked network by terminalcrosslinking, is believed to be responsible for this result.

In conclusion, we have introduced the terminally-crosslinked sulfonated poly(fluorenyl ether sulfone) (PFES) as a novel PEM. The dimensionally stable polymer electrolyte, having combined benefits of both the bulky fluorenyl unit and the terminallycrosslinked network, offers high proton conductivity and yet very low methanol permeability even at increased temperature. We believe that these results have proved its potential availability as an electrolyte for both high temperature PEMFC and DMFC.

Acknowledgments. This work was supported by the National Research Foundation of Korea(NRF) grant funded by the Korea government (MEST) (2010-0016521) and a grant from the Korea Institute of Science and Technology as a part of the "Development of Fuel Cell Power-packs for Portable Power Generation” program (2E21570-10-034).

\section{References}

1. Samms, S. R.; Wasmus, S.; Savinell, R. F. J. Electrochem. Soc. 1996, 143, 1498.

2. Saito, M.; Arimura, N.; Hayamizu, K.; Okada, T. J. Phys. Chem. B 2004, 108, 16064.

3. Arico, A. S.; Srinivasan, S.; Antonucci, V. Fuel Cells 2001, 133.

4. Higashihara, T.; Matsumoto, K.; Ueda, M. Polymer 2009, 50, 5341.

5. Hickner, M. A.; Ghassemi, H.; Kim, Y. S.; Einsla, B. R.; Mcgrath, J. E. Chem. Rev. 2004, 104, 4587.

6. Ueda, M.; Toyota, H.; Ochi, T.; Sugiyama, J.; Yonetake, K.; Masuko, T.; Teramoto, T. J. Polym. Sci. 1993, 31, 853.

7. Kerres, J. A. J. Membr. Sci. 2001, 185, 3.

8. Kerres, J. A. Fuel Cells 2005, 5, 230.

9. Mikhailenko, S. D.; Wang, K.; Kaliaguine, S.; Xing, P.; Robertson, G. P.; Guiver, M. D. J. Membr. Sci. 2004, 233, 93.

10. Fang, J.; Shen, P. K.; Liu, Q. L. J. Membr. Sci. 2007, 293, 94.

11. Yin, Y.; Fang, J.; Cui, Y.; Tanaka, K.; Kita, H.; Okamoto, K.-i. Polymer 2003, 44, 4509.

12. Oh, Y.-S.; Lee, H.-J.; Yoo, M.; Kim, H.-J.; Han, J.; Kim, K.; Hong, J.-D.; Kim, T.-H. Chem. Commun. 2008, 2028.

13. Oh, Y.-S.; Lee, H.-J.; Yoo, M.; Kim, H.-J.; Han, J.; Kim, T.-H. J. Membr. Sci. 2008, 323, 309.

14. The dramatic enhancement in conductivity for the crosslinked membrane at higher temperature was ascribed to a structural reorganization occurred at hydrated and heated conditions, promoting a formation of free volumes with sulfonic acid groups for the crosslinked polymer. This is further detailed. Thankamony, R. L.; Lee, M.-G.; Lee, H.-J.; Kim, K.; Kim, H.-J.; Nam, S.; Lim, Y.-b.; Kim T.-H. Macromol. Res. in press.

15. Change in thickness: $11.9 \%$ and in length: $4.0 \%$ for PFES-50; $13.3 \%$ (in thickness) and $6.4 \%$ (in length) for PFES-50n; $18.9 \%$ (in thickness) and $13.5 \%$ (in length) for Nafion ${ }^{\circledR}-117$. 